Hoyles, C., \& Noss, R, (2015) A computational lens on design research in Prediger, S. Gravemeijer K., \& Confrey, J. (eds) Design research with a focus on learning processes: an overview on achievements and challenges. ZDM. 877. Volume: 47. Issue: 6. pp 1039 -1045.

\title{
A Computational Lens on Design Research
}

Celia Hoyles \& Richard Noss

London Knowledge Lab

UCL Institute of Education, University College London

\begin{abstract}
In this commentary, we briefly review the collective effort of design researchers to weave theory with empirical results, in order to gain a better understanding of the processes of learning. We seek to respond to this challenging agenda by centring on the evolution of one sub-field: namely that which involves investigations within a constructionist framework of learning with carefully designed computational tools. We argue that these studies, specifically those where children were learning to program, were early adopters of the Design Research methodology and offer a useful lens through which to focus on the current field.
\end{abstract}

\section{Introduction}

In our collective effort as researchers to weave theory with empirical results in order to gain a better understanding of mathematical learning processes and practices, it is appropriate to take stock of how we got here, 
Hoyles, C., \& Noss, R, (2015) A computational lens on design research in Prediger, S. Gravemeijer K., \& Confrey, J. (eds) Design research with a focus on learning processes: an overview on achievements and challenges. ZDM. 877. Volume: 47. Issue: 6. pp 1039 -1045.

and where we might go next, particularly as the breadth and depth of mathematics education research has grown at such a pace. It is increasingly difficult for any researcher to read all the relevant literature on any topic at stake, not least as the categorisation of research methodologies has changed over the years. We therefore very much welcome this Special Issue. It offers, through its various contributions, new insights into instructional design in mathematics. Crucially for the community, it draws together several strands of work in the Design Research (DR) paradigm, thus ensuring that the antecedents of this research methodology - or more accurately families of methodologies are richly documented. We anticipate that this Special Issue will serve as a springboard for building on and elaborating these strands of work, perhaps in different learning contexts, as well as motivating the articulation and establishment of other categories of DR research.

We start with the origin of DR, as suggested by Prediger, Gravemeijer, \& Confrey (2015), who state:

“... first-generation instructional design theories were tailored to the linear model and assumed fixed learning goals, ample academic knowledge, and directly applicable general theories. Design research ideas emerged in situations where first-generation instructional theories fell short; they are tailored to more innovative learning environments, where learning goals are to be refined in the process, little academic knowledge is available, and general theories do not yet offer much help..."pp

This insight has implications for our field. Primarily, it forces us to recognise that innovation poses particular challenges for research: the necessity to take particular care explicitly to link theory to methodology, to be constantly aware of unexpected outcomes, and yet to maintain systematicity and methodological rigour. Setting goals must be the first 
Hoyles, C., \& Noss, R, (2015) A computational lens on design research in Prediger, S. Gravemeijer K., \& Confrey, J. (eds) Design research with a focus on learning processes: an overview on achievements and challenges. ZDM. 877. Volume: 47. Issue: 6. pp 1039 -1045.

step in systematic research, even if it is recognised that they might be provisional and need to be modified iteratively as a result of the research. Thus, researchers need to decide where to start iterative cycles of research, and even more difficult, where to stop! Lobato et al. (2015) make an important contribution to this methodological challenge on how to leverage failure in DR, reminding us of the two dimensions of potential failure in DR:
"Failure can be conceived as an unexpected breakdown that has negative consequences for student learning (e.g., Collins et al. 2004). Alternatively, failure can be regarded as the inability of current theory to account for discoveries in the data (e.g., diSessa \& Cobb 2004). Correspondingly, early failures are leveraged, respectively, to improve instructional artifacts or to generate new theoretical constructs. " (Lobato, et al, 2015). pp

The framework for DR proposed in the seminal paper by Cobb et al. (2003), includes 'prospective endpoints' (p.11) as key facets in preparing for a design experiment. Others go further to discuss the "notion of hypothetical learning trajectory (HLT)" (Simon (1995). Margolinas \& Drijvers (2015), in their comparison of didactical engineering in France and design research in the Netherlands, suggest: "HLT is a theoretical construct that originally refers to the teacher's prediction as the path by which learning might proceed" $p p$. An outstanding challenge for DR perhaps, is for researchers to explore iterative changes in these trajectories and the triggers for any deviations. Stephan (2015) develops the notion of HLT further, through the idea of "classroom learning trajectory" which he describes as follows:

I use the term classroom learning trajectory to refer to the hypothesized learning route developed by a class of students as they interact with one another and a teacher rather than an individual learning trajectory 
Hoyles, C., \& Noss, R, (2015) A computational lens on design research in Prediger, S. Gravemeijer K., \& Confrey, J. (eds) Design research with a focus on learning processes: an overview on achievements and challenges. ZDM. 877. Volume: 47. Issue: 6. pp 1039-1045.

which is created by an individual in a one-on-one experiment with a teacher or researcher. p.xx

What is important in the above is that any formulation points to the strong epistemological element of DR, an early recognition of the what of teaching and learning and not only the how. As a corollary, therefore, a key facet of DR research was and is that it should illustrate for any given case - "the relationships among the theoretical underpinnings and the development of local theory with respect to topic-specific learning processes" (Prediger et al., 2015). In other words, we should surely know more about learning and teaching interactions of the particular topic as a result of the design research, resulting in "better materials and learning": but we should also know more about the mathematics itself and the instructional process more generally. This Special Issue provides many instances: see, for example, Confrey \& Maloney (2015), who identify two 'humble theories' to describe perspectives on student learning; de Beer, Gravemeijer \& van Eijck 2015, who offer the term initial local instruction theory (LIT), which is elaborated and refined in the DR paradigm; and Prediger \& Krägeloh (2015) who give an example of the employment of DR for understanding students' comprehension strategies for algebraic word problems, in which the specification of the comprehension strategies is refined successively.

It is interesting to ponder a generalisation of the goals of DR. Building 'things' - concepts or frameworks - simultaneously improves the 'things', and our understanding of them. Readers of this Special Issue might recognise here the constructionist mantra that learning is most effective when learners build and share: it is constructionism applied to research methodology as well as learning. Observing students assemble and construct their ideas using (digital) tools thus provides an opportunity 
Hoyles, C., \& Noss, R, (2015) A computational lens on design research in Prediger, S. Gravemeijer K., \& Confrey, J. (eds) Design research with a focus on learning processes: an overview on achievements and challenges. ZDM. 877. Volume: 47. Issue: 6. pp 1039 -1045.

for researchers to construct local theories, opening a window on their thinking-in-change (see Noss \& Hoyles, 1996 for an elaboration of the 'windows' metaphor). This idea is developed by the contribution of Abrahamson (2015), who argues that DR is in fact usefully conceived as a constructionist approach to educational research:

"I believe that adults, too, best construct knowledge when they construct artifacts in the public domain, and this includes educational researchers constructing experimental learning materials. I thus view design research as a constructionist approach to educational research: researchers best construct theory when they construct artifacts for students and reflect on solutions to emergent problems encountered in so doing." (Abrahamson, 2015: p.xx).

It is thus worthwhile to explore further the relationship between constructionism and DR, given the affinity between them. Constructionism is listed in the introductory paper of the Special Issue as a "background" theory (like e.g. genetic epistemology, constructivism, constructionism, socio-cultural approaches and situated learning" (Prediger et al., 2015, pp ). Clearly there is considerable variation in the nature of these theories. In fact the theoretical status of constructionism is itself debated: a theory of learning but also of instruction, that 'building knowledge occurs best through building things that are tangible and sharable". (Ackerman et al., 2009: 56). However the theory of constructionism has become elaborated in practice through the design and evaluation of learning in computer-based environments. It has become clear that this constructive technology-based research shares many points of contact with design research, particularly from a methodological standpoint. Of course, constructivism and its variations do likewise, emphasising that theory and problems drive the development of 
Hoyles, C., \& Noss, R, (2015) A computational lens on design research in Prediger, S. Gravemeijer K., \& Confrey, J. (eds) Design research with a focus on learning processes: an overview on achievements and challenges. ZDM. 877. Volume: 47. Issue: 6. pp 1039 -1045.

methodology: methods respond from the need to investigate real problems and challenges and unknowns ${ }^{1}$.

To sum up, in our view, constructionist technology-based research was an early adopter of what latterly became known as DR, and may even have influenced its development. We therefore welcome the opportunity to introduce the reader to some early, but we hope still informative, work, which may assist in plugging a gap in the history of the DR methodology. We have wondered about the reasons for this historical gap. It is certainly the case that research with technology has in the past often been relegated to a silo apart from other research in mathematics education and interpreted as research about technology. We argued some time ago that:

We are aware of an implicit barrier between the study of mathematical learning in computer-mediated settings, and that which employs traditional, inert media. [...] It might be that the concerns of the two communities are somewhat different: and for some part of the last two decades, this might well have been the case. Or there might be a deeper reason; it may be that with any new technology (film, video, or 'hypermedia'), initial attention is focused on the technology itself, rather than on what might be done with it. Even those who resist this temptation can easily be ignored as sharing technical, rather than educational, goals; and perhaps they (we?) have not always been guiltless in this respect. (Noss \& Hoyles 1996, pp. 8-9)

Clearly using digital technology is now more integrated into classroom practice and frequently forms either part of the design of instructional activities, or as a tool in the research process. This Special issue includes some notable contributions in the area of computer-supported mathematics education, with the technology used in a variety of ways:

\footnotetext{
${ }^{1}$ We are grateful to Jere Confrey for helping us to clarify this point.
} 
Hoyles, C., \& Noss, R, (2015) A computational lens on design research in Prediger, S. Gravemeijer K., \& Confrey, J. (eds) Design research with a focus on learning processes: an overview on achievements and challenges. ZDM. 877. Volume: 47. Issue: 6. pp 1039 -1045.

Gresalfi uses an online, interactive videogame; Kwon et al. use software that allows students to observe and manipulate graphs to explore partial differentiation; de Beer et al. use a computer simulation of filling glassware; Confrey et al. use a tablet-based diagnostic assessment system to generate feedback to the students and the teacher, and to exploit a chatfunction to support collaborative work.

However we would like to briefly revisit and reflect on a strand of DR, not named as such at the time but nevertheless fitting the criteria developed in the future. This is the research field of programming and mathematics, where the program itself captures the mathematical relationships at stake. In fact, this is particularly pertinent in 2015 when programming - or 'coding' - is becoming ubiquitous in informal learning and code clubs in many countries. In England, programming is manifest in school practice, with a statutory National Curriculum for computing (since September 2015) along with mandatory programming courses at all school levels in England. It might therefore be timely for the research community to revisit the potential of programming and mathematics using more explicitly the lens of DR. Here we simply raise this as an issue for reflection and discussion in the future.

\section{DR in a programming context}

The case for programming and mathematics is nicely put by diSessa (2001) who argued that it "turns analysis into experience and allows a connection between analytic forms and their experiential implications that algebra and even calculus can't touch" (ibid., p. 34). More generally, learning to program has been shown to be an engaging activity for most children: they become more autonomous as they build, learn from feedback and debug. As a historical note, over the years since its 
Hoyles, C., \& Noss, R, (2015) A computational lens on design research in Prediger, S. Gravemeijer K., \& Confrey, J. (eds) Design research with a focus on learning processes: an overview on achievements and challenges. ZDM. 877. Volume: 47. Issue: 6. pp 1039 -1045.

inception in 1996, the International Journal of Computers for Mathematical Learning has produced some fascinating examples relevant here under the headings of "Computer Math Snapshots". They exemplify an important but under-researched element of constructionist methodologies focusing on the epistemological dimension-what becomes learnable when the computer is designed as an integral component of the learning process. Moreoever, we note that unless the activities are carefully designed, managed and sequenced, there might not be positive learning outcomes or trajectories, and there is an added risk that only advantaged learners - mainly boys - show learning gains (Yelland \& Rubin, 2002).

As time has passed, the potential for learning mathematics through programmable tools has become more evident with, for example, the development of high-level languages such as Mathematica, powerful dynamic geometry and statistical software and so on. On a theoretical level, many have theorised that such computer tools should be conceived as a means of with new mathematical meanings created by tool use (see for example Bartolini Bussi, \& Mariotti, 2008). Olive et al. (2010) went further to propose technology as a fourth vertex for Steinbring's (2005) "didactic triangle", in order to illustrate metaphorically how the interactions among student, teacher, task and technology form the 'space within which new mathematical knowledge and practices may emerge' (ibid. p.169).

A common theme in this strand of research is that learning evolves in ways that are contingent on design, of the activities presented to the students, but also the software. In addition, it was increasingly recognised how student learning is deeply sensitive to the interface in software design, as well as the tasks, activity structures and pedagogical 
Hoyles, C., \& Noss, R, (2015) A computational lens on design research in Prediger, S. Gravemeijer K., \& Confrey, J. (eds) Design research with a focus on learning processes: an overview on achievements and challenges. ZDM. 877. Volume: 47. Issue: 6. pp 1039 -1045.

context. Thus we identify in this research strand a shift away from studying the possibilities of expressing mathematical relationships within a language towards a stronger focus on designing curricular systems that exploit the expressive potential of these languages.

Significant progress has been made on understanding how sets of programmable tools or microworlds, might be interconnected, manipulated and modified in pursuit of mathematical learning goals and with what outcomes. In this respect, programming-based research undertook a more explicit shift to take on board the framework of DR: after all, the iterative development of a microworld can surely be considered as a piece of DR in itself. As Hoyles (1993) put it, a powerful way to think about the microworld idea is a vision in which "software tools and knowledge would grow together interactively in the pursuit of epistemologically rich goals" (ibid. p. 3).

\section{An example of early DR in a programming environment}

To make these ideas concrete, we revisit and summarise an example of early DR in this area. One area in which we have employed DR (a descriptor we would claim now but not then) was designing and evaluating the learning outcomes of interactions in a programming microworld around the critical but difficult idea of proportionality. The microworld comprised a set of progressively more challenging tasks designed so it made sense to express the multiplicative relations of proportionality generally and formally (using the symbolic language of a programming language) and in which the computer feedback would draw attention to any incorrect strategies.

The task of the researchers was to investigate the meanings of ratio and proportion articulated by a group of thirteen-year-old students while 
Hoyles, C., \& Noss, R, (2015) A computational lens on design research in Prediger, S. Gravemeijer K., \& Confrey, J. (eds) Design research with a focus on learning processes: an overview on achievements and challenges. ZDM. 877. Volume: 47. Issue: 6. pp 1039-1045.

interacting in this (Logo) microworld, and to try to understand how their evolving thinking was influenced by their computer interactions. The design principles included exploiting the potential of Logo to bring together symbolic and graphical representations. Our experience had shown that working with Logo tended to throw up ideas of ratio and proportion rather naturally: for example, once procedures for drawing figures had been built, students often posed for themselves the issue of enlarging or shrinking them. Hoyles (1989) for example, showed how students used the Logo idea of input as a scale factor (a scalar operator) to change the size of a drawing in proportion and built general procedures in ways that reflected the internal relationships between figures (functional operators).

One task in the microworld, as illustration, was a sequence of letter N's with vertical sides of length 150, 350 and 100 units each with an angle of 30, (see Figure 1). Students were asked to predict the length of the diagonal of each $\mathrm{N}$, build a Logo procedure for each $\mathrm{N}$ and try it out. Finally they were asked to generalise and write a procedure for say, $45^{\circ}$ N's. The intention was to encourage students to express and generalise what they perceived to be the invariant relationship between the lengths and angles of the family of N's.
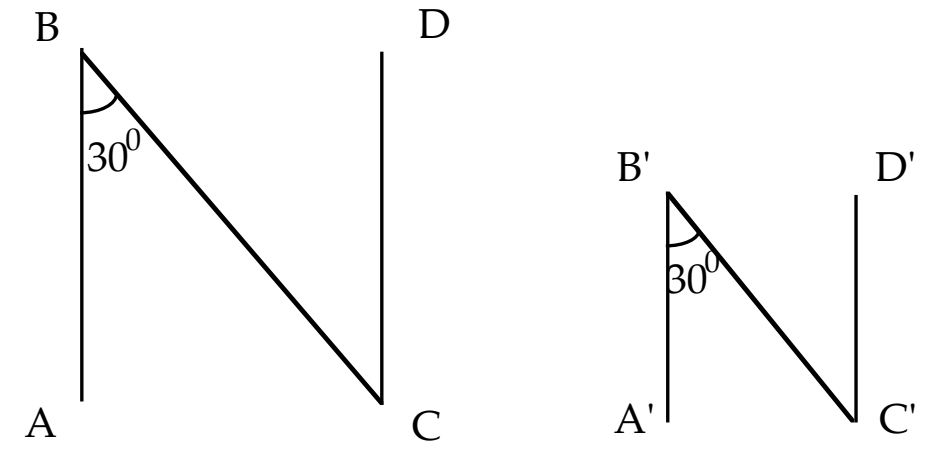

Figure 1: Two proportional $30^{\circ}$ N's 
Hoyles, C., \& Noss, R, (2015) A computational lens on design research in Prediger, S. Gravemeijer K., \& Confrey, J. (eds) Design research with a focus on learning processes: an overview on achievements and challenges. ZDM. 877. Volume: 47. Issue: 6. pp 1039 -1045.

What did we expect the children to do? First we drew on the research studies that existed at that time, (1987), all based on pencil and paper of course, and set out our predictions for children's strategies. We classified likely strategies based on this prior research, for example noting the 'additive strategy' in which equal amounts are added to each length to make a larger figure. We draw the readers' attention to the micro-level task design in which the connection between proposed interaction and mathematical ideas was knitted together as tightly as possible. At this point, we could only assume that these strategies would be independent of the medium in which they would be expressed. However on analysis of the student data, we were surprised to find (albeit in our small sample) that there was no computer behaviour analogous to the otherwise ubiquitous additive strategy.

The main point here is to point to how this early work indicated how mathematical learning is shaped by the nature of the tools of expression. In particular, we concluded that unexpected levels of generality can emerge from computer interactions, and that formalisation in quasialgebraic terms - in the form of computer code - had become a means of thinking about and expressing relationships, rather than merely summing up already-understood relationships. We characterised these unexpected levels of generality as 'situated abstractions' - abstractions expressed in the medium of activity rather than in mathematical discourse -- without maybe recognising sufficiently and explicitly that this idea was as much epistemological as cognitive in character, (see Noss \& Hoyles, 1996, for more on situated abstraction; and the AERA interactive symposium on abstraction in mathematics learning, Lobato et al, 2005.)

At the time, the methodological conclusion was that working with carefully designed tasks in Logo could make a qualitative difference to 
Hoyles, C., \& Noss, R, (2015) A computational lens on design research in Prediger, S. Gravemeijer K., \& Confrey, J. (eds) Design research with a focus on learning processes: an overview on achievements and challenges. ZDM. 877. Volume: 47. Issue: 6. pp 1039 -1045.

how students expressed proportionality. Reflecting now on this early corpus of work ${ }^{2}$, we suggest that it may usefully be considered it as comprising examples of DR, although a more rigorous and self-conscious approach with a clearer theoretical underpinning alongside more precise analyses of learning outcomes and trajectories might now be possible: the research field has moved on so much in the intervening years. ${ }^{3}$ A strong characteristic of this early research work was however considerable uncertainty concerning the knowledge at stake and how it could be expressed: just how does the computer presence alter not only how learning takes place, but the very nature of what is learned? At the ICMI study (Hoyles \& Lagrange, 2010) "Mathematics Education and Technology—Rethinking the Terrain", Seymour Papert issued a call for researchers to allocate " $10 \%$ of their time" to consider these questions of epistemology. In fact, in the working groups of the conference, it became clear just how challenging was Papert's proposal.

A further challenge, (also raised in the ICMI study mentioned above, Hoyles \& Lagrange, 2010: section 2), arose from the recognition that the teacher had been a relatively neglected player in digitally oriented research, where the focus had tended to be on the individual doing mathematics with software. We now turn to this issue.

\footnotetext{
${ }^{2}$ See, for example, the volumes of International Journal of Computers for Mathematical Learning over the last two decades.

${ }^{3}$ While we acknowledge the need for rigorous methodology and data analyses, we believe it is important not to lose the inspirational ideas catalysed by work with programming: as examples, see for example Papert, 1996; Sfard \& Leron, 1996; Wilensky \& Rand, 2015å; and many others.
} 
Hoyles, C., \& Noss, R, (2015) A computational lens on design research in Prediger, S. Gravemeijer K., \& Confrey, J. (eds) Design research with a focus on learning processes: an overview on achievements and challenges. ZDM. 877. Volume: 47. Issue: 6. pp 1039 -1045.

\section{The role of the teacher and the challenge of scaling an innovation}

We acknowledge that early design research with computers - including our own - often failed to include detailed investigation of the role of the researchers and teachers. This was and is partly due to the magnitude of the task - software and activity design alongside research in schools, with each focus of research demanding different skills, methodologies and resources. Today, few researchers working within the DR paradigm would argue against the need for careful attention to the critical role of teachers in any study, and the papers in this Special Issue attest to this. However, this does brings further complexity to research, as attention has to be turned towards the challenge of what might be appropriate teacher support and how teachers can most fruitfully be part of any design research scenario. The challenges for teachers' continuing professional development (CPD) are numerous, as outlined in a previous ZDM issue (Roesken-Winter et al. 2015). They are not central to the discussion here. We note here just one interesting example: Stephan (2015) describes an approach where teachers not only are members of the research team, but also lead the implementation, sharing some aspects with the tradition of action research.

On a personal level, our interest has always been in researching innovation that is co-designed with teachers as part of a collaborative network, an acknowledgement that might appear to leave out how much teachers are already designers: anyone who has closely watched a classroom will be aware that teachers take hundreds of decisions per hour that evolve into a (sometimes implicit) design framework. Viewed this way, the challenge for researchers might best be conceptualised, not so much as helping teachers to learn (with the new tools and through the 
Hoyles, C., \& Noss, R, (2015) A computational lens on design research in Prediger, S. Gravemeijer K., \& Confrey, J. (eds) Design research with a focus on learning processes: an overview on achievements and challenges. ZDM. 877. Volume: 47. Issue: 6. pp 1039 -1045.

new activities), or even as participants in the design effort, but as developing strategies so that the design criteria and associated teacher and student learning outcomes stand in alignment to each other without loss of epistemological fidelity - a tall order. We suggest that it is only in this way that there is any possibility of the innovation becoming genuinely embedded in practice and sustainable. This argument is also central to the contribution by Cobb \& Jackson (2015), who suggest that innovations should be designed with an eye on large-scale implementation from the start. They identify the "aspects of the school context that need to be addressed by a dissemination design, such as school instructional leadership and teachers' access to colleagues who have already developed relatively accomplished instructional practices". p. $\mathrm{xx}$

Teacher ownership necessitating some adaptation is critical in addressing the problem of evolving innovation beyond the specific project or study. But how can this be operationalized within a constructionist technologybased DR framework, not least, as there is a welcome recognition in the field that transformational change involves what might be called accommodation rather than assimilation on the part of teachers? Again by reference to Cobb \& Jackson (2015): How can support be offered that is 'close enough' to instructional practice yet at the same time seek to change it.

DR in the digital context has taken a leading role in focussing on the process of instrumental genesis (Vérillon \& Rabardel, 1995) in order to make explicit not only the intention of technology use, but to understand its role in situ, how tools shape and are shaped by practice transforming the learning and teaching of the knowledge at stake. However more broadly, an innovation cannot be thought of as a single entity that simply 
Hoyles, C., \& Noss, R, (2015) A computational lens on design research in Prediger, S. Gravemeijer K., \& Confrey, J. (eds) Design research with a focus on learning processes: an overview on achievements and challenges. ZDM. 877. Volume: 47. Issue: 6. pp 1039 -1045.

enters unchanging into the complex ecology of the learning and teaching process. It 'mutates', a metaphor proposed by Hung et al. (2010). Mutations range from the 'legitimate' to the 'lethal', describing the extent to which classroom implementations adhere or not to the innovation's original design principles. But adherence to the researchers' original design intentions cannot, surely, be a sufficient criterion for success: legitimate adaptations might also enhance the epistemic value of the innovation as its use is customised to the context of implementation (Hoyles et al. 2013). We conclude by a few comments on this study, Cornerstone Maths $(\mathrm{CM})$ in which we have recently been involved.

$\mathrm{CM}$ studied the learning processes around what we aimed to be a sustainable and scalable intervention (including a professional development resource), which embeds dynamic technology in specifically designed activities. In CM, the DR work has highlighted the critical importance of multiple forms of goal-alignment, which begin with the aspirations and classroom practices of the individual teachers, but extend to consider their institutional settings at departmental, school, local and national levels. As part of our continuing DR effort in CM, we have come to appreciate the full impact on teachers and on student learning at the micro-level of macro-educational factors such as policymakers' preferences and goals, which in the case of the use of digital technology sometimes takes us well outside the orbit of mathematics and mathematics education: for example, to introduce hardware and connectivity across the country on the one hand, or to react to the results of comparative studies, on the other. With another lens, we note just how sensitive the question of alignment is to the initial conditions of the individual's dispositions: an example is of one $\mathrm{CM}$ teacher who effectively had no alignment to perform - her school's 
Hoyles, C., \& Noss, R, (2015) A computational lens on design research in Prediger, S. Gravemeijer K., \& Confrey, J. (eds) Design research with a focus on learning processes: an overview on achievements and challenges. ZDM. 877. Volume: 47. Issue: 6. pp 1039 -1045.

'project-based' approach fitted nicely with her personal style and with the expressed goals of CM, and she had no real process of alignment to do; another, by contrast, had to 'convert' the school management and his colleagues to the goals of the CM innovation (Clark-Wilson, et al, 2015)

Acknowledging this kind of reciprocity between innovation, context, knowledge and belief is partly responsible for the power of the ecological metaphor in charting the spread of an innovatory virus: Confrey et al (2015) refer to Cobb et al 's (2003) notion of "a complex learning ecology" as a study whose elements include:

the tasks or problems that students are asked to solve, the kinds of discourse that are encouraged, the norms of participation that are established, the tools and related material means provided, and the practical means by which classroom teachers can orchestrate relations among these elements (p. 9).

This ecological metaphor is an appropriate point to end this foreword. By stressing the complexity and - above all - the inter-relationships between the different elements that shape an intervention, we briefly outline where we - as design researchers - might go next. Our ultimate goal remains to enhance the learning of mathematics and engagement with the subject. It is, of course, dangerous to speculate: but one possible new strand of the design research methodology might be to strengthen the 'mixed-methods' research framework by building an even stronger complementarity between qualitative and quantitative data analyses by harnessing emerging techniques of big data and learning analytics. These techniques are slowly but surely yielding interesting insights, having initially been primarily focused on mere collection of what was collectible. Now it is becoming clearer what problems big data might solve, as well as begin to solve them. It is not inconceivable that such an approach, adopted by 
Hoyles, C., \& Noss, R, (2015) A computational lens on design research in Prediger, S. Gravemeijer K., \& Confrey, J. (eds) Design research with a focus on learning processes: an overview on achievements and challenges. ZDM. 877. Volume: 47. Issue: 6. pp 1039 -1045.

interdisciplinary teams - a further major challenge - might help to tame the ever growing complexity of design research that focuses on learning as it takes place in classrooms, schools and school systems, and beyond.

\section{References}

Abrahamson, D. (2015). Reinventing Learning: A Design-Research Odyssey. ZDM Mathematics Education, 47(6), doi 10.1007/s11858-0140646-3 (this issue).

Bartolini Bussi, M. G., \& Mariotti, M. A. (2008), Semiotic mediation in the mathematics classroom: artifacts and signs after a Vygotskian perspective, in: Handbook of International Research in Mathematics Education, second revised edition, L. English, M. Bartolini Bussi, G. Jones, R. Lesh, and D. Tirosh, eds., Lawrence Erlbaum, Mahwah, NJ., pp. 746-805

Ackerman E. et al., (2009) Constructivism(s): shared roots, crossed paths, multiple legacies. Proceedings of Constructionism, Paris, 2012

Clark-Wilson A., Hoyles C., Noss, R., Vahey P., \& Roschelle J. (2015) Scaling a technology-based innovation: windows on the evolution of mathematics teachers' practices. In ZDM: Mathematics Education Roesken-Winter, B, Hoyles C, Blömeke, S (Eds) 2015, Evidence-based CPD: Scaling up sustainable interventions ZDM: Mathematics Education, 47(1). Springer. ISSN: 1863-969

Clements, D. \& Sarama, J. (1997). Logo a retrospective. Special Issue of Computers in the Schools Volume 14 Issue 1-2, Pages 9-46

Cobb, P. \& Jackson, K. (2015). Supporting teachers' use of researchbased instructional sequences. ZDM Mathematics Education, 47(6), doi 10.1007/s11858-015-0692-5 (this issue). 
Hoyles, C., \& Noss, R, (2015) A computational lens on design research in Prediger, S. Gravemeijer K., \& Confrey, J. (eds) Design research with a focus on learning processes: an overview on achievements and challenges. ZDM. 877. Volume: 47. Issue: 6. pp 1039-1045.

Cobb, P., Confrey, J., diSessa, A., Lehrer, R., \& Schauble, L. (2003).

Design experiments in education research. Educational Researcher, 32(1), 9-13.

Confrey, J. \& Maloney, A. (2015). A Design Study of a Curriculum and Diagnostic Assessment System for a Learning Trajectory on Equipartitioning. ZDM Mathematics Education, 47(6). (this issue).

de Beer, H., Gravemeijer, K., \& van Eijck, M. (2015). Discrete and continuous reasoning about change in primary school classrooms. ZDM Mathematics Education, 47(6), doi 10.1007/s11858-015-0684-5 (this issue).

diSessa, A. A. (2001). Changing minds: Computers, learning and literacy. Cambridge, MA: MIT Press.

diSessa, A.. and P. Cobb (2004). Ontological innovation and the role of theory in design experiments. Journal of the Learning Sciences 13 (1), 77-103.

Gresalfi, M. (2015). Designing to support critical engagement with statistics. ZDM Mathematics Education, 47(6), doi 10.1007/s11858-0150690-7

Hoyles, C. (1993). Microworlds/schoolworlds: the transformation of an innovation. In C. Keitel, \& K. Ruthven (Eds.), Learning from computers: mathematics education and technology. (pp. 1-17). Berlin; New York: Springer-Verlag.

Hoyles, C. and J.-B. Lagrange (eds.) (2010). In: Mathematics Education and Technology-Rethinking the Terrain. The 17th ICMI Study. New York: Springer. 
Hoyles, C., \& Noss, R, (2015) A computational lens on design research in Prediger, S. Gravemeijer K., \& Confrey, J. (eds) Design research with a focus on learning processes: an overview on achievements and challenges. ZDM. 877. Volume: 47. Issue: 6. pp 1039-1045.

Hoyles, C. and Noss, R., eds. (1992). Learning Mathematics and Logo. Cambridge Ma: MIT Press.

Hoyles, C., \& Noss, R. (1989). The Computer as a Catalyst in Children's Proportion Strategies. Journal of Mathematical Behaviour, 8, 53-75.

Hoyles, C., Noss, R., Vahey, P., \& Roschelle, J. (2013). Cornerstone mathematics: designing digital technology for teacher adaptation and scaling. ZDM Mathematics Education, 45(7), 1057-1070.

Hung, D., Lim, K., \& Huang, D. (2010). Extending and scaling technology-based innovations through research: The case of Singapore. In: Organisation for Economic Co-operation and Development (Ed.), Inspired by technology, driven by pedagogy [electronic resource]: a systemic approach to technology-based school innovations (pp. 89-102): OECD Publishing.

Kwon, O.N., Bae, Y.G., \& Oh, K.H. (2015). Design Research on InquiryBased Multivariable Calculus: Focusing on Students' Argumentation and Instructional Design. ZDM Mathematics Education, 47(6), doi ??? (this issue).

Lobato, J., Noss, R., Hoyles, C., Cobb, P.. Schwarz B, Dreyfus T, Hershkowitz R. \& Sfard, A. (2005). Abstraction in Mathematics Learning: Comparing Alternative Emerging Conceptions. AERA Division C-3 Interactive Symposium.

Lobato, J., Walters, C. D., Hohensee, C., Gruver, J, \& Diamond, J.M. (2015). Leveraging Failure in Design Research. ZDM Mathematics Education, 47(6), doi 10.1007/s11858-015-0695-2 (this issue).

Margolinas, C. \& Drijvers, P. (2015). Didactical engineering in France; an insider's and an outsider's view on its foundations, its practice and its 
Hoyles, C., \& Noss, R, (2015) A computational lens on design research in Prediger, S. Gravemeijer K., \& Confrey, J. (eds) Design research with a focus on learning processes: an overview on achievements and challenges. ZDM. 877. Volume: 47. Issue: 6. pp 1039 -1045.

impact. ZDM Mathematics Education, 47(6), doi 10.1007/s11858-0150698-z (this issue).

Noss R. \& Hoyles, C. (1996) Windows on mathematical meanings: Learning cultures and computers. Dordrecht: Kluwer

Olive, J. \& Makar, K. et al. (2010) Mathematical Knowledge and Practices Resulting from Access to digital technologies. In: Hoyles, C. and J.-B. Lagrange (eds.) (2010): Mathematics Education and Technology-Rethinking the Terrain. The 17th ICMI Study. New York: Springer. pp. 133-157.

Papert, S. (1991). Situating constructionism. In I. Harel \& S. Papert (Eds.), Constructionism (pp. 1-12). Norwood: Ablex Publishing

Papert, S. (1996). An exploration in the space of mathematics educations. International Journal of Computers for Mathematical Learning 1, 1, 95 123.

Prediger, S. \& Krägeloh, N. (2015). Low achieving eighth graders learn to crack word problems: a design research project for aligning a strategic scaffolding tool to students' mental processes. ZDM Mathematics Education, 47(6), doi 10.1007/s11858-015-0702-7 (this issue).

Prediger, S., Gravemeijer, K. \& Confrey J., (2015) Design research with a focus on learning processes. ZDM Mathematics Education, 47(6), doi ?? (this issue).

Roesken-Winter, B, Hoyles C, Blömeke, S (Eds) (2015). Evidencebased CPD: Scaling up sustainable interventions ZDM: The International Journal of Mathematics Education (47(1)). Springer. ISSN: 1863-969

Sfard, A. \& Leron, U. (1996). Just give me a computer and I will move the earth: programming as a catalyst of a cultural revolution in the 
Hoyles, C., \& Noss, R, (2015) A computational lens on design research in Prediger, S. Gravemeijer K., \& Confrey, J. (eds) Design research with a focus on learning processes: an overview on achievements and challenges. ZDM. 877. Volume: 47. Issue: 6. pp 1039 -1045.

mathematics classroom. International Journal of Computers for Mathematical Learning. 1(2), 189-195.

Sfard, A. \& Leron, U. (1996). Just give me a computer and I will move the earth: programming as a catalyst of a cultural revolution in the mathematics classroom. International Journal of Computers for Mathematical Learning. 1(2), 189-195.

Simon, M.-A. (1995). Reconstructing mathematics pedagogy from a constructivist perspective. Journal for Research in Mathematical Education, 26, 114-145.

Steinbring H. (2005) The construction of new mathematical knowledge in classroom interaction: An epistemological perspective. NY: Springer.

Stephan, M. L (2015). Conducting classroom design research with teachers. ZDM Mathematics Education, 47(6), doi 10.1007/s11858-0140651-6 (this issue).

Vérillon, P., \& Rabardel, P. (1995). Cognition and artifacts: A contribution to the study of thought in relation to instrumented activity. European Journal of Psychology of Education, 10(1), 77-101

Wilensky, U. \& Rand, W. (2015). An Introduction to Agent-Based Modeling: Modeling Natural, Social, and Engineered Complex Systems with NetLogo. Cambridge, MA. MIT Press.

Yelland N. and Rubin A. (2002) (Eds), Ghosts in the Machine: Women's Voices in Research and Technology. New York: Peter Lang Publishing. 